\title{
Selection of Tolerant of Some Citrus Hybrids F1 to Calcareous Stress and Identification Sexuall Individuals by SSR Marker
}

\author{
Venus Ebraheem Hasan ${ }^{1 *}$, Ali Issa Elkhateeb ${ }^{1}$, Hassan Yosef Khojah ${ }^{2}$ \\ ${ }^{1}$ General Commission Agriculture Scientific Research, Lattakia, Syria \\ ${ }^{2}$ Horticulture Department, Agriculture College, Tishreen University, Lattakia, Syria \\ Email: *venushasan80@gmail.com
}

How to cite this paper: Hasan, V.E., Elkhateeb, A.I. and Khojah, H.Y. (2022) Selection of Tolerant of Some Citrus Hybrids F1 to Calcareous Stress and Identification Sexuall Individuals by SSR Marker. American Journal of Plant Sciences, 13, 60-82. https://doi.org/10.4236/ajps.2022.131005

Received: December 8, 2021

Accepted: January 15, 2022

Published: January 18, 2022

Copyright $\odot 2022$ by author(s) and Scientific Research Publishing Inc. This work is licensed under the Creative Commons Attribution International License (CC BY 4.0).

http://creativecommons.org/licenses/by/4.0/

(c) (i) Open Access

\begin{abstract}
The research was conducted during two seasons 2018-2019 and 2019-2020, at the Scientific Research Center in Lattakia-Syria, where the cross between Sour orange, Cleopatra mandarin and Trifoliate orange. The first season was (Sour orange $\hat{\delta} \times$ Cleopatra mandarin + ) and (Cleopatra mandarin $\hat{\delta} \times$ sour orange + ) and (sour orange $\hat{\delta} \times$ trifoliate orange + ), and the crossing in the second season was (Trifoliate orange $\hat{\sigma} \times$ Sour orange + ), and (Trifoliate orange $\hat{\delta} \times$ Cleopatra mandarin $q$ ). The plants of the first generation $\mathrm{F} 1$ were exposed to calcareous stress according to two methods. The first one for a long term (two years) method was grown in plots containing 15\% and 35\% Calcium Carbonate and the control free of Calcium Carbonate for the first cross, and the second one short term (two months) by watering method was with a solution of $1 \mathrm{~mol}$ and $2 \mathrm{~mol}$ of Calcium Carbonate for the second cross. The indicators of proline and chlorophyll A, B and T were measured in the first-generation individuals, once at the beginning of the experiment and a second time at the end of study. Seven SSR primers were used to identify sexual individuals, five primers were able to identify sexual $\mathrm{F} 1$ individuals are CSM13, CSM17, CSM147, CSM18 and TAA27, F1 individuals in the first season (mixture experiment) gave high values of chlorophyll and were tolerant to calcareous stress from crossing Cleopatra mandarin and Sour orange, where they did not show a deterioration in chlorophyll, but rather increased chlorophyll values, and the Trifoliate orange hybrids were sensitive to this stress, and in the watering experiment the F1 showed significant deterioration in Chlorophyll in all seedlings, and symptoms of Lime-induced chlorosis appeared on the more sensitive seedlings.
\end{abstract}

\section{Keywords}

Citrus Rootstock, Calcareous Stress-Hybridization, SSR Markers-Proline, 


\section{Introduction}

In Syria, Citrus is important fruit tree, it's $42 \%$ of total fruit production (Figure 1) [1]. It is mainly cultivated in Lattakia, but suffers from Lime-induced chlorosis in calcareous soils that contain high concentrations of $\mathrm{HCO}_{3}$-bicarbonate in the soil solution, which causes a high $\mathrm{pH}(7.5$ - 8.5), and affects the metabolic processes in roots and leaves of citrus [2]. The genus Citrus belongs to the family of Rutaceae and subfamily of Aurantioideae [3].

Rootstocks have a major role in the success of citrus cultivation because they play an important role in the growth, development and production [4]. More than 20 horticultural characteristics are influenced by the rootstock including adaptation to certain soil conditions such as high $\mathrm{pH}$ [5]. Sour orange is one of the most major rootstocks in Citrus fruits, but it began to be dispensed with after CTV (Citrus Tristeza Virus). However, in Syria, it is still the only rootstock in citrus nurseries.

Hybridization in citrus aims to obtain tolerant rootstocks to biotic and abiotic stresses [6]. The problem of high calcium carbonate in the soil is also one of the most important nutrition problems [7]. Cultivation of economic citrus cultivars on suitable rootstock tolerant of environmental conditions is one of the environmentally friendly techniques [8] [9].

The aim of this research is to evaluate the F1 individuals, then select the more tolerant to Lime-induced chlorosis, by chemical indicators. Hybridization carried out three parents namely: Sour orange, Cleopatra mandarin and Trifoliate orange, then, identification the nucellar (asexual) and zygotic (sexual) seedlings of F1 by PCR based SSR markers.

Proline is one of the most abundant amino acids in the tissues of Citrus. It contains a non-free amino group (NH2). It is an important soluble nitrogen solution in citrus leaves [10]. Proline accumulation is important primary indicator in determining the degree of tolerance of plants to abiotic stresses and has a

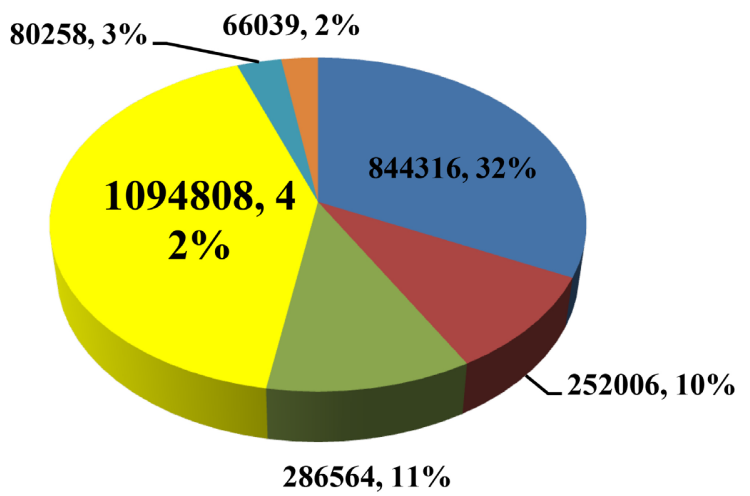

- Olive

- Grape

$\because$ Apple

Citrus

Almond

- Cherries

Figure 1. Production/ton of fruits in Syria. 
role as protective osmolyte compound at the cellular level in the internal osmotic adjustment of plants exposed to stress [11] [12]. It usually accumulates in plant tissues in response to its adaptation or sensitivity to certain stresses such as low temperatures, salinity or lack of water, and this can be known early during the plant cycle. Increasing the level of Proline content protects the plant from stress but also acts as part of a cascade of signals to alter plant development [13]. It is a protective factor against swelling and tolerant rootstocks can accumulate larger amounts of Proline [14]. Tolerant genotypes released more Proline than sensitive ones, there is a relationship between the resistance of the genotype to a specific stress state with the amount of accumulated amino acids, Proline accumulated in the root can be used as an early sign of the degree of stress tolerance, as the plant may not accumulate proline in the leaves to a large extent if it is not stressed enough to accumulate it [15].

Chlorophyll is the basic pigment that performs photosynthesis by absorbing light and converting it into chemical energy, so life on Earth depends largely on chlorophyll [16].

The ratio of chlorophyll A to chlorophyll B in plants has been used as an indicator of response to light shade conditions [17] [18], The low value of chlorophyll A/B refers to sensitive genotype to environmental stress [19]. The color of Citrus leaves varies greatly from dark green to light green, due to the amount of chlorophyll in the leaves, and even in the same plant, it varies according to the growing season, the maturity of the leaf, light intensity, nutrition, stress and rootstock. However, after exposure to various stresses, chlorophyll begins to break down, and in general, is affected by the stresses [20] [21]. Chlorophyll shows damage at a high level of stress [22]. Lime-induced chlorosis in the Mediterranean region is one of the main abiotic stresses affecting fruit trees [23]. [24] studied the chlorosis of 16 rootstocks in high $\mathrm{pH}$ conditions in growth chambers and found that Sour orange, Cleopatra mandarin was the most tolerant, Pomeroy trifoliate (Pon) trifoliata var. Pomeroy), was sensitive and the local Trifoliate orange was most sensitive to calcareous soil and high $\mathrm{pH}$. The researchers note that the Trifoliate suffers more severely from chlorosis than the other rootstocks, while Cleopatra mandarin orange was showed little or no symptoms of chlorosis [24] [25] [26]. The values of total chlorophyll were significantly higher in resistant rootstock than in sensitive ones [24].

Microsatellites or simple sequence repeats are short sequence composed of repeat units one to seven basepairs [27]. These sequences are highly polymorphic and used in population genetics [28], and genome mapping [29]. SSR markers are becoming popular due to high polymorphism, co-dominance, simplicity of analysis and repeatability [30]. Conventional breeding of citrus plants is slow and difficult, mainly because of the complex reproductive biology, involving polyploidy, high heterozygosis and single gene inheritance patterns in a few traits. Also, prolonged juvenile periods of seedling in the field make citrus breeding very lengthy. Molecular-based markers have been used to construct 
linkage maps, identify genotypes and distinguish hybrids from nucellar seedlings, An important constraint in citrus breeding programmes is apomixes. Apomictic embryos arising from the nucellar tissue give rise to seedlings that are genetically identical to seed parents thus yielding uniform offspring for propagation [31]. In most of the crossing combinations, aimed at citrus improvement, it would not be possible to determine the genetic origin of seedlings from morphology. Identification of young seedlings is very essential for the plant breeders to avoid 5 - 10 years' cost of growing and maintaining unwanted nucellar seedlings. Thus, it is mandatory to identify the zygotic seedlings while discarding the nucellar ones for smooth running of citrus breeding programmes. Genetic studies using microsatellite markers have increased rapidly because these are highly polymorphic, heterozygous conserved sequences that can be used as co-dominant markers [32].

[33] evaluated primeres CSM17, CSM147, CSM13, CSM18 in distinguishing hybrids from nucelling seedlings caused by Citrus. reticulata Blanco. and they gave high efficacy. [34] also used SSR indicators to identify the sexual from asexual of Mexican lemons seedlings from previous cross-breeding programs for disease resistance, such as the CTV and Huanglongbing (greening) that were threatened in citrus cultivation.

\section{Material and Methods}

\subsection{Plant Material}

Hybridization has been made between three Citrus rootstocks:

Citrus aurantium L. (Sour orange), it is good compatibility with commercial cultivars, and tolerant of calcareous soils [35].

Citrus reticulata Blanco (Cleopatra mandarin), It is tolerant of high $\mathrm{pH}$, calcareous soils [36].

Poncirus trifoliata (L.) Raf. (Trifoliate orange)

It is deciduous rootstock, becoming very dormant and extremely freeze-hardy, used as a rootstock in cold regions [37]. It is an important genetic source for Citrus rootstocks genetic improvement programs, for stress tolerance and diseases resistance [38]. Important rootstocks were obtained by cross-breeding between Citrus and Trifoliate orange [39].

\subsection{Hybridization}

The crosses were carried out for two successive seasons 2018-2019 and 2019-2020 during March and April of each season, more than 1500 flowers for each seed parent, and the crosses were as Table 1.

The hybrid seeds of Sour orange and Cleopatra mandarin were planted in February, and hybrid seeds of Trifoliate orange at September, according to the date of ripening of the fruits of the first season, within a specific code for each of them with symbols A, B and C, where the symbol A refers to the hybrid Trifoliate orange (seed parent), and were given the numbers A1-A2- using Sour 
Table 1. Crosses carried out.

\begin{tabular}{cccc}
\hline code & Pollen parent $\delta$ & Seed parent + & Season \\
\hline A & Sour orange & Trifoliate orange & \\
C & Trifoliate orange & Sour orange & 2019-2018 Season 1 \\
B & Sour orange & Cleopatra mandarin & \\
S & Trifoliate orange & Sour orange & 2019-2020 Season 2 \\
K & Trifoliate orange & Cleopatra mandarin & \\
\hline
\end{tabular}

orange as a pollen parent. Cleopatra mandarin (seed parent) hybrids were given the numbers B1-B2 and the Sour orange was also (pollen. parent), while the Sour orange hybrids (seed parent) were given the numbers $\mathrm{C} 1-\mathrm{C} 2-$ and the pollen parent was Trifoliate orange. In the second season, the seeds from the hybridization were sown in a sterile tube and placed at a temperature of $27^{\circ} \mathrm{C}$, at the end of February, the symbol S refers to the Sour orange hybrids and the symbol $\mathrm{K}$ to the Cleopatra mandarin hybrids. The Trifoliate orange was the pollen seed in both cases, and the Sour orange hybrid was given the numbers S200, S201..., etc., and the Cleopatra mandarin hybrid the numbers K1, K2..., etc. The number associated with the code indicates the hybrid number.

Hybrids were transferred to $2 \mathrm{~kg}$ planting pots containing an earthen mixture consisting of turb, sand and soil in equal proportions.

1) Season 1, 2018-2019: The hybrid seedlings for the first season of crossing were transferred in April 2019 to previously prepared soil mixtures according to Table 2.

2) Season 2, 2019-2020: As for the f1 individuals of the second season, were transferred in September 2019 to $2 \mathrm{~kg}$ agricultural pots and soil containing traces of calcium carbonate to start the experiment of the calcareous stress watering at the beginning of October. The treatments were as Table 3.

\subsection{Studied Indicators}

\section{Proline}

The proline content of leaves was measured before stress and after stress according to [40].

proline $\mathrm{mg} / \mathrm{g}$ plant tissue $=\frac{\text { extention } \times \text { volum of extraction solution } \times \text { concentration } \mathrm{ppm}}{\text { sample solution volum } \times \text { weight extract sample } \times 1000}$

\section{Chlorophyll}

Chlorophyll will be extracted according to [41]. Chlorophyll A, chlorophyll B and total chlorophyll were calculated according to equations:

$$
\begin{aligned}
& \text { mg chlorophyll a } / g \text { tissue }=\frac{12.7(A 663)-2.69(A 645) \times V}{1000 \times W} \\
& \text { mg chlorophyll b/g tissue }=\frac{22.9(A 645)-4.68(A 663) \times V}{1000 \times W}
\end{aligned}
$$

chlorophyll $\mathrm{T}=$ chlorophyll $\mathrm{a}+$ chlorophyll $\mathrm{b}$ 
Table 2. Mixtures of calcareous stress.

\begin{tabular}{ll}
\hline Treatment A & $\begin{array}{l}\text { Soil that does not contain calcium carbonate }+15 \% \text { calcium carbonate } \\
+100 \mathrm{~g} \text { turb }\end{array}$ \\
Treatment B & $\begin{array}{l}\text { Soil that does not contain calcium carbonate }+35 \% \text { calcium carbonate } \\
+100 \mathrm{~g} \text { turb }\end{array}$ \\
\hline
\end{tabular}

Table 3. Treatment of calcareous stress (watering).

\begin{tabular}{ll}
\hline Treatment M1 & $\begin{array}{l}\text { Watering with calcium carbonate solution } 1 \text { mol twice, first time in } 1 \\
\text { October and second in 1 November }\end{array}$ \\
Treatment M2 & $\begin{array}{l}\text { Watering with calcium carbonate solution } 2 \text { mol twice, first time in } 1 \\
\text { October and second in } 1 \text { November }\end{array}$ \\
\hline
\end{tabular}

$A$ : Absorbance at a given wavelength.

$V$ : Final volume of chlorophyll extract.

$W$ : Fresh weight of the plant tissue from which chlorophyll was extracted.

\section{DNA Extraction}

DNA was extracted by QIAGEN DNeasy Plant Mini Kit, immediately after leaf collection.

7 SSR primer pairs were tested on 11 DNA samples; 4 parents and 7 individuals f1.

\section{Amplification by PCR}

Fragment sizes of PCR products in a total volume of $25 \mu \mathrm{L}$ solution containing $3 \mu \mathrm{L}$ DNA, $1 \mu \mathrm{L}$ of primers (10 p/mol), $12.5 \mu \mathrm{L}$ of Taq PCR Master Mix KIT, (2.5 units Taq DNA Polymerase)-1xQIAGEN PCR Buffer $200 \mu \mathrm{M}$ of each dNTP), 8.5 $\mu \mathrm{L}$ sterile distilled water. Samples were subjected to PCR program consisted of $94^{\circ} \mathrm{C}$ predenaturation for 5 minutes, $94^{\circ} \mathrm{C}$ denaturation for 30 seconds, $49^{\circ} \mathrm{C}$ $54^{\circ} \mathrm{C}$ annealing for 45 seconds ( $T a b l e 4$ ), $72^{\circ} \mathrm{C}$ extension for 1 minute 35 cycles and $72^{\circ} \mathrm{C}$ extension 10 minutes. The products were stored in negative $20^{\circ} \mathrm{C}$ freezer.

\section{Electrophoresis}

PCR products were analyzed using 2 percent agarose gel\% (1\% agarose and $1 \%$ PeqGold MoSieve Agarose) containing ethidium bromide. Fragment sizes of PCR products were estimated from the gel by comparison with 50-base pair DNA ladder marker. The bands were recorded as present (1) or absent (0) and complied into a two-way matrix (accession $\times$ marker), were estimated from the gel by comparison with 50-base pair DNA ladder marker.

\subsection{Statistical Analysis}

The significant differences between the values of the studied indicators (Proline, Chlorophyll) before and after the stress were calculated using the T-student for the linked samples.

Criticale Difference was calculated to determine the significant difference of the studied indicator in the special coping ability of the individuales after exposure to stress. 
Table 4. SSR primers used for PCR-Amplification of genomic DNA extracted from F1 seedlings of citrus (eurofins Genomics mer company).

\begin{tabular}{ccc}
\hline Primers & Primers Sequences (5’'3’) $\mathbf{F}$ & Primers Sequences (5’'-3’) $\mathbf{R}$ \\
\hline CCSM17 & ACATGGACAGGACAACTAAG & GTTATGATACGTCTGTGTCC \\
CCSM147 & GCTATGTTATGATACGTCTG & AGACTCACGTAACCTACTTC \\
CCSM18 & GTGATTGCTGGTGTCGTT & AACAGTTGATGAAGAGGAAG \\
CCSM13 & CTAGAGCCGAATTCACC & AACAGCTACCAAGACACC \\
TTA27 & GGATGAAAAATGCTCAAAATG & TAGTACCCACAGGGAAGAGAGC \\
TTA15 & GAAAGGGTTACTTGACCAGGC & CTTCCCAGCTGCACAAGC \\
TTA33 & GGTACTGATAGTACTGGGGGG & GCTAATGCTAGGTCTTCGC \\
\hline
\end{tabular}

The dendograms were made from the identification of presence (1) or absence (0) of bands using the five primers, through the unweighted paired grouping method with arithmetic means (UPGMA) and squared Euclidean distance. The analyzes were carried out with the use of the statistical package Numerical Taxonomy and Multivariate Analysis System (NTSYS-pc 3.2) [42].

The molecular seedlings were compared with the profile of the mother for ascertaining the nature of the seedling.

\section{Results}

\subsection{Proline Indicator}

1) Season 1:

\section{Calcareous stress $15 \%$}

In the $15 \%$ calcareous stress, the highest accumulation of proline is $0.83 \mathrm{mg} / \mathrm{g}$ for individual A11, 0.78 for $\mathrm{C} 14$ and 0.74 for A14, A24, B17, B7, B15, and A13, and the lowest accumulation is 0.61 for $\mathrm{B} 4$, we note that the individuals that deteriorated have also accumulated Proline such as A27 with a 1.28, the $\mathrm{C} 12$ has 0.73 , and the $\mathrm{C} 15$ has 0.72 (Figure 2). The difference in the values of Proline before and after stress is significant; Critical Difference indicated that the individual A11 was significantly superior at the level of $1 \%$ over B4, no significant difference with the rest of the individuals.

\section{Calcareous stress $35 \%$}

The highest value of Proline at $35 \%$ calcareous stress is $(0.76,0.75,0.74) \mathrm{mg} / \mathrm{g}$ plant in individuals C11, C10 and A12, respectively, while the lowest of Proline is 0.41 for hybrid A7. Critical Difference indicated that hybrid C11 is significantly superior at the $1 \%$ level over individuals B18, B3, A6 and A7, no significant difference with the rest of the individuals, the difference in the values of Proline before and after stress is significant (Figure 3).

\section{2) Season 2}

\section{Calcareous stress $1 \mathrm{~mol}$}

The highest value of Proline is (2.43) $\mathrm{mg} / \mathrm{g}$ in the hybrid S102 (sour orange 9 ) before exposure to stress (Figure 4). 


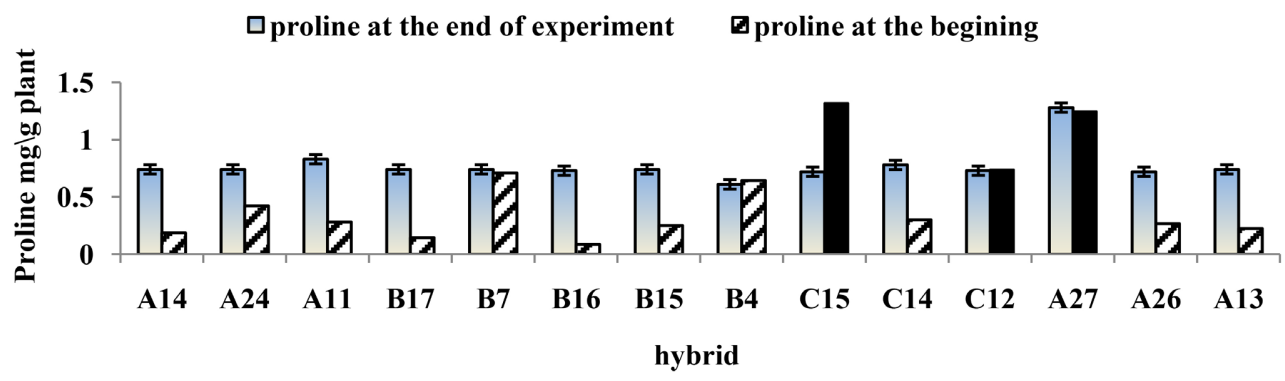

Figure 2. Concentration of proline before calcareous stress $15 \%$ and at the end of experiment.

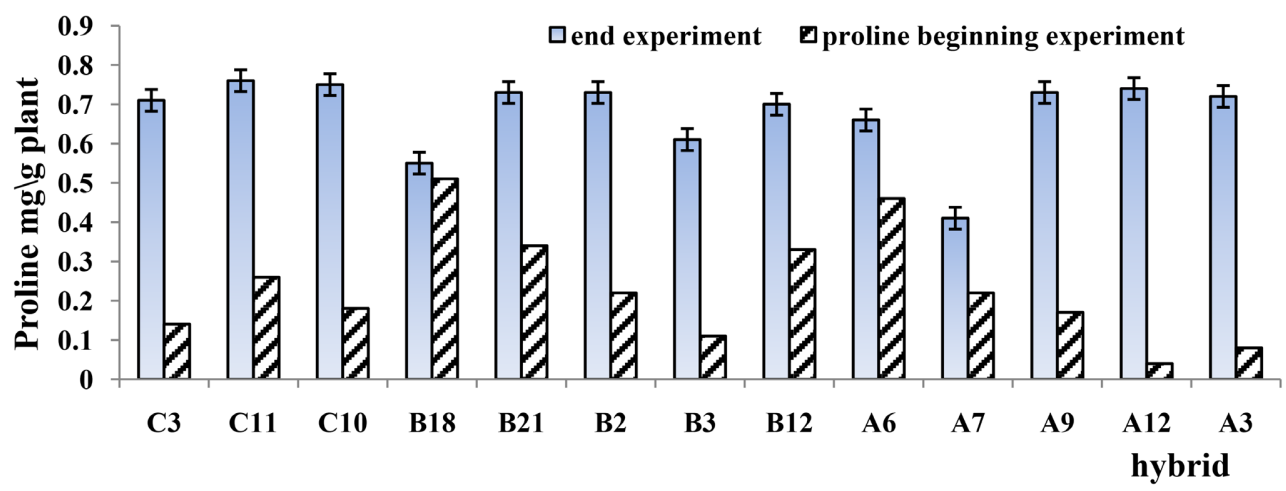

Figure 3. Concentration of proline before calcareous stress $35 \%$ and at the end of experiment.

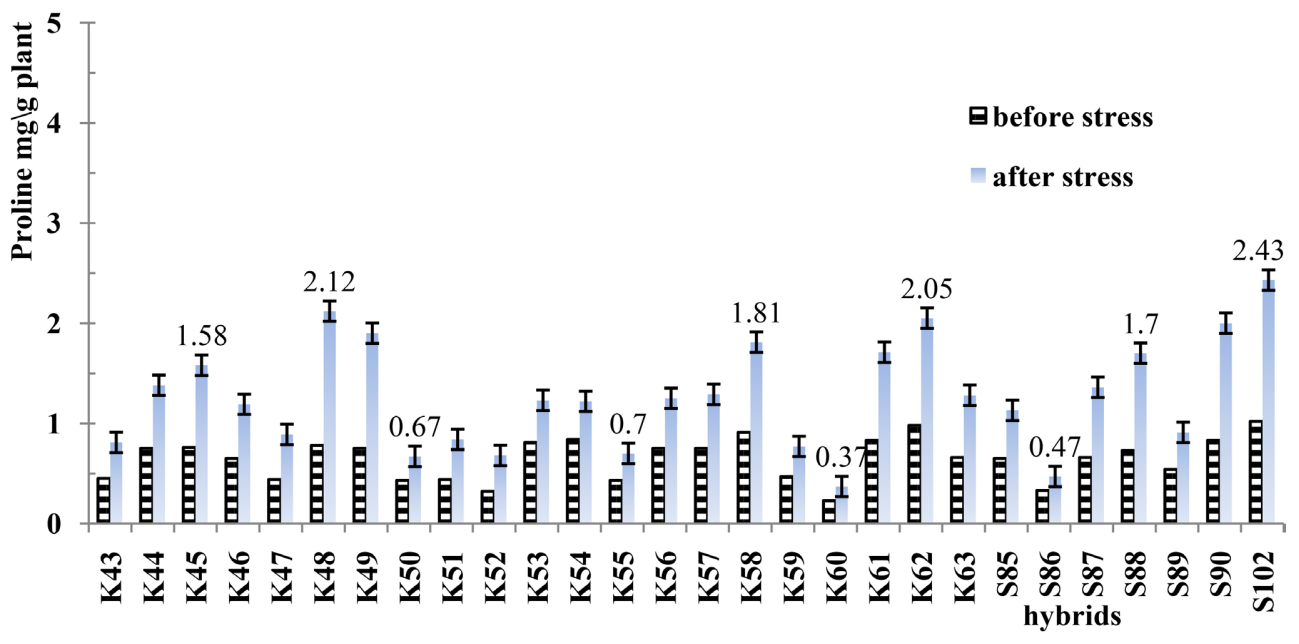

Figure 4. Accumulation proline in the individuals exposed calcareous stress 1 mol.

The F1 individuals accumulate Proline after 1 mol. stress, and superiority compared with it before stress with a high significance. The Critical difference indicated that hybrid S102 outperformed all crosses with a high significance, and hybrid K48 outperformed all crosses except hybrids K49, K62 and S90, no significant difference between the last one.

\section{Calcareous stress $2 \mathrm{~mol}$}

Proline accumulation in the plants after stress at concentration (2) mol with a high statistical significance, and the highest value is (4.22) in the K78 hybrid, (2.33) in K71 hybrid, (2.22) in (K79), and (1.88) in hybrid (S96). The lowest ac- 
cumulation of Proline was reached (0.27) in hybrid S100, and (0.28) in hybrid (K67) (Figure 5).

Critical Difference indicates that superiority of hybrid K78 (seed parent Cleopatra mandarin) over the rest of the crosses, and the superiority of hybrid K71 (seed parents Cleopatra mandarin) over all hybrids except K80 and K79, there are no significant differences between the latter.

\subsection{Chlorophyll}

1) Season 1

\section{Calcareous stress $15 \%$}

Chlorophyll A

The highest concentration of Chlorophyll A after $15 \%$ stress is 1.24, 0.95, 0.92 and $0.92 \mathrm{mg} / \mathrm{g}$ for the A11, B15, B7 and A24 hybrids respectively. It increases at the end of the experiment in hybrids A11, B7 and B15 compared to its concentration on the first date. However, the concentration of chlorophyll A decreased in the rest of the crosses. There is no significant difference in the amount of chlorophyll A in individuals exposed to stress 15\% (Figure 6).

Chlorophyll B

There is a significant difference in the concentration of Chl. B at $15 \%$ stress, the highest concentration of it is $0.55 \mathrm{mg} / \mathrm{g}$ for hybrid B17 (Figure 7), because tolerant of its parent seed (Cleopatra mandarin + ), and 0.54, 0.53 for hybrids A14 (sour orange ${ }^{\lambda}$ ) and B15 respectively. The lowest value is 0.25 for hybrid B4 and 0.32 for hybrid B16, and there are many hybrids that have deteriorated and exited from the experiment such as A27 and C15.

Clorophyll T

There are no significant differences in the Chl. $\mathrm{T}$ in the date 2 compared with date 1 (Figure 8), the highest concentration is 1.61 and 1.48 for hybrid A11 and $\mathrm{B} 15$, respectively, and the lowest value was 0.78 for hybrid B4.

Calcareous stress $35 \%$

Chlorophyll A

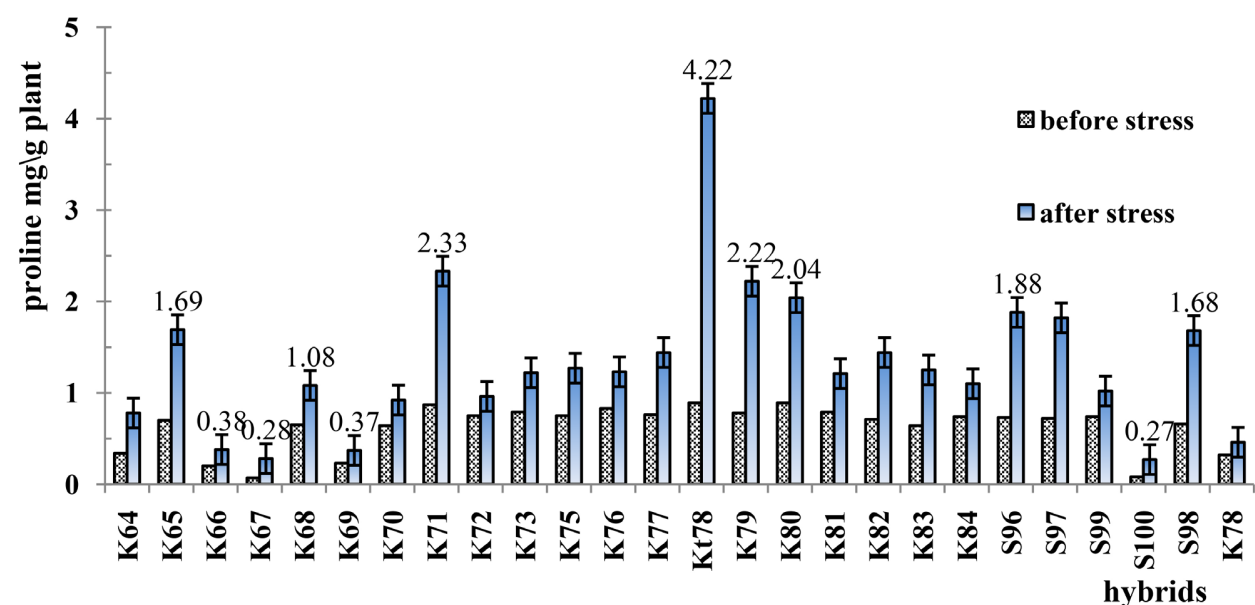

Figure 5. Accumulation of proline at the individuals exposed calcareous stress 2 mol. 


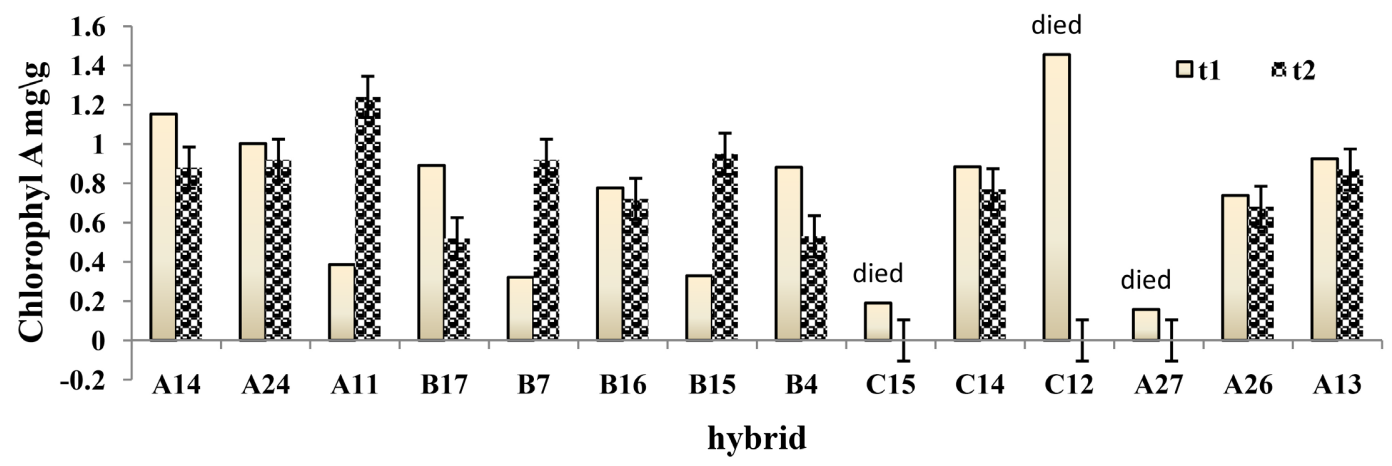

Figure 6. Chlorophyll A concentration in two dates, the first after six months of the experiment and the second at the end of the experiment after two years at $15 \%$ calcium stress.

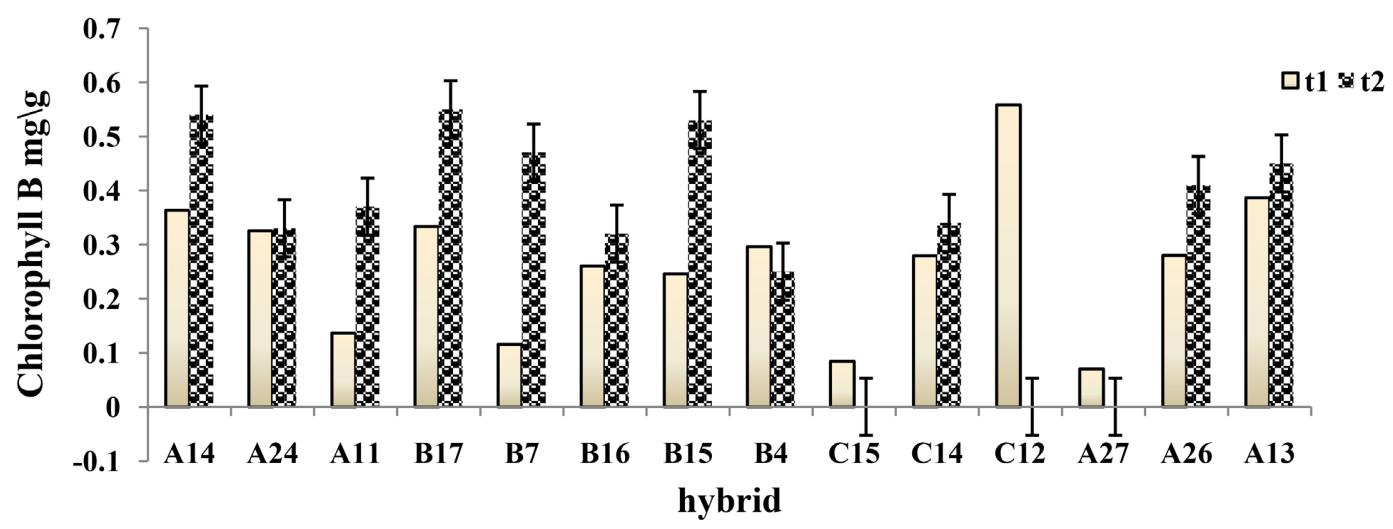

Figure 7. Chlorophyll B concentration in two dates, the first after six months of the experiment and the second at the end of the experiment after two years at $15 \%$ calcium stress.

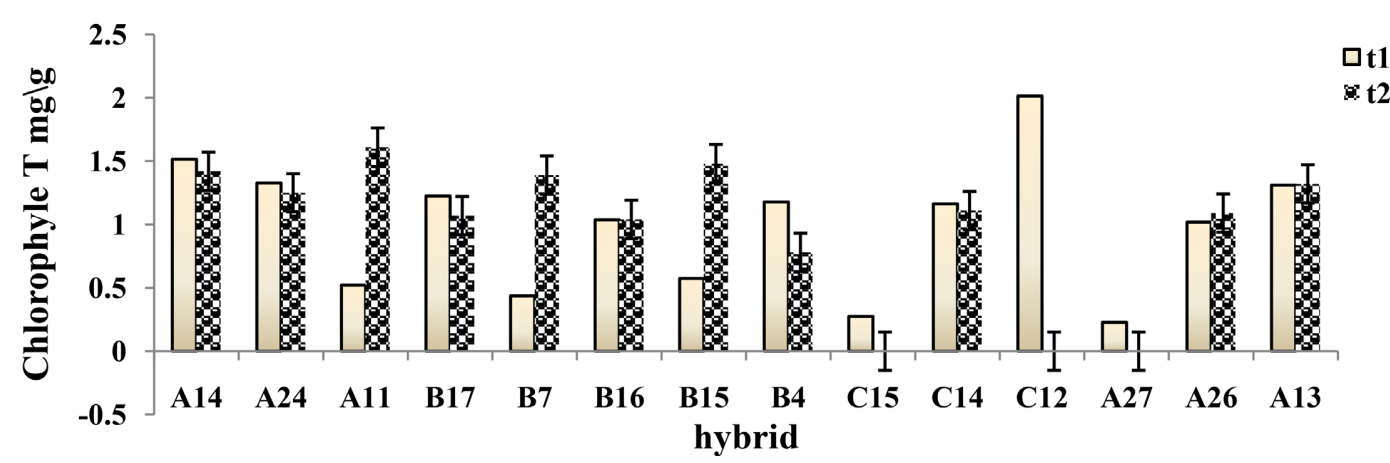

Figure 8. Chlorophyll $\mathrm{T}$ concentration in two dates, the first after six months of the experiment and the second at the end of the experiment after two years at $15 \%$ calcium stress.

Calcareous stress caused the deterioration of Chl. A in most of plants, that there is no significant difference in the concentrations of Chl. A in the two dates according to T-student.

It decreased at the second date compared to the first one clearly in most of the hybrids except for C3, B3, B21 and C11. There are differences in the decreased among the individuals, because each hybrid is a new individual with new specifications that vary with other. The higher value of Chl. A is $(1.81,1.45) \mathrm{mg} / \mathrm{g}$ of hybrids B21 (Sour orange $\hat{O} \times$ Cleopatra mandarin + ) and C3 (Cleopatra man- 
darin $\hat{O} \times$ Sour orange + ), whereas both of Sour orange and Cleopatra mandarin are tolerant to calcareous stress, 0.96 for the A12 hybrid, and 0.88 for hybrids $\mathrm{C} 10$ and $\mathrm{A} 9$, however the lowest concentration is 0.46 for hybrid B12 (Figure 9).

Chlorophyll B

The concentration of chlorophyll B decreased of the individuals, as a result of calcareous stress in some of it, and in others increased, such as the hybrid C3 (Cleopatra mandarin $\widehat{\partial}$, Sour orange + ), B21, B2, B3 (Sour orange $\widehat{\partial}$, Cleopatra mandarin + ), A9 (Sour orange $\hat{\delta}$, Trifoliate orange $q$ ), this is due to that each hybrid is an independent genetic structure and differs from the other individuals with its characteristics, its tolerant stress, and the inheritance of this trait of tolerance to calcium stress from the parents. The highest value is $(1.8,1.27) \mathrm{mg} / \mathrm{g}$ for hybrids B21 and C3, respectively and 0.76 for the A9 hybrid. The lowest value is 0.16 for hybrid B12, no significant differences for the value of chl. B measured in the two mentioned dates according to T-student (Figure 10).

Chlorophyll T

The highest value of total chlorophyll is 3.61 and $2.72 \mathrm{mg} / \mathrm{g}$ plant for B21 and C3, respectively, it increased, these two hybrids have both Sour orange and Cleopatra mandarin tolerant parents, and 1.64 and 1.5 for A9 and B3. The minimum amount of total chlorophyll is 0.62 for B12, it decreased as a result of stress, but it is not significant (Figure 11).

2) Season 2

\section{Calcareous stress $1 \mathrm{~mol}$}

Chlorophyll A

The Chl. A decreased after stress with a high statistical significance (Figure 12).

Chlorophyll B

Chl. B in all individuals destructs after calcareous stress with a high statistical significance. The highest value of Chl. B is $(0.761,0.813$ and 0.663$) \mathrm{mg} / \mathrm{g}$ of (S89, $\mathrm{K} 50$ and S85) respectively. The lowest concentration of Chl. B is (0.015 and 0.029) $\mathrm{mg} / \mathrm{g}$ of (K49 and K46) respectively. According Critical Difference, that hybrids S89, S85, and K50 are significantly superior to all hybrids, no significant difference between S89, K50, and between S89, S85 (Figure 13).

Chlorophyll T

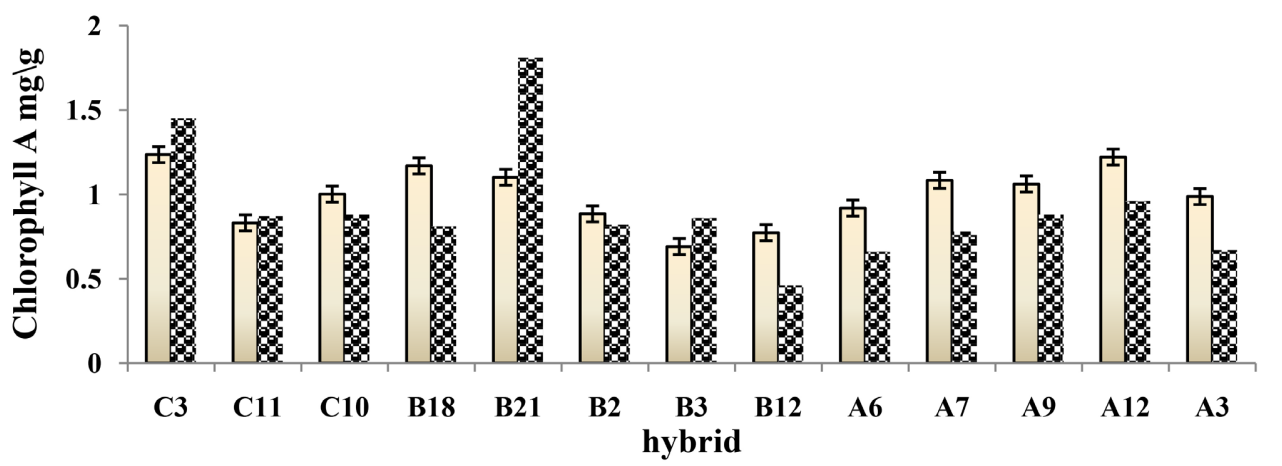

Figure 9. Chlorophyll A concentration in two dates, the first after six months of the experiment and the second at the end of the experiment after two years at $35 \%$ calcium stress. 


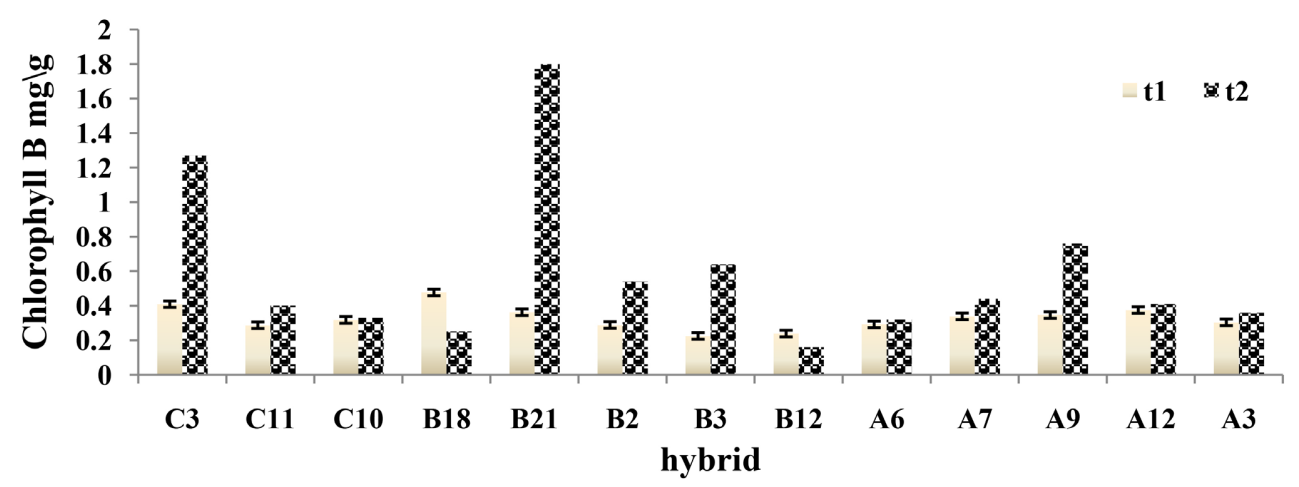

Figure 10. Chlorophyll B concentration in two dates, the first after six months of the experiment and the second at the end of the experiment after two years at $35 \%$ calcium stress.

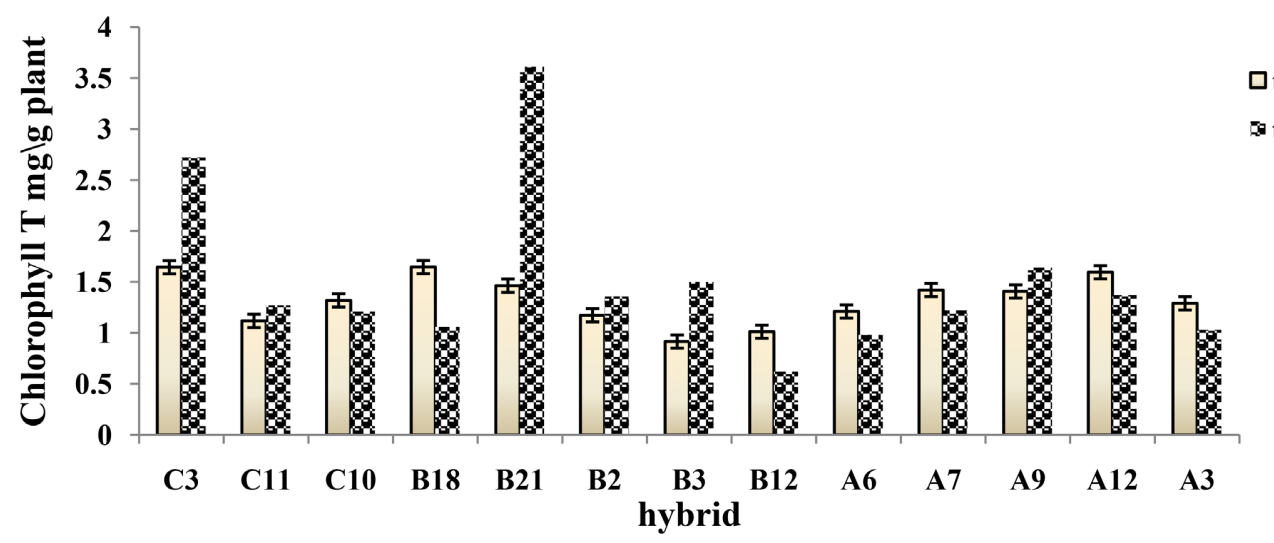

Figure 11. Chlorophyll $\mathrm{T}$ concentration in two dates, the first after six months of the experiment and the second at the end of the experiment after two years at $35 \%$ calcium stress.

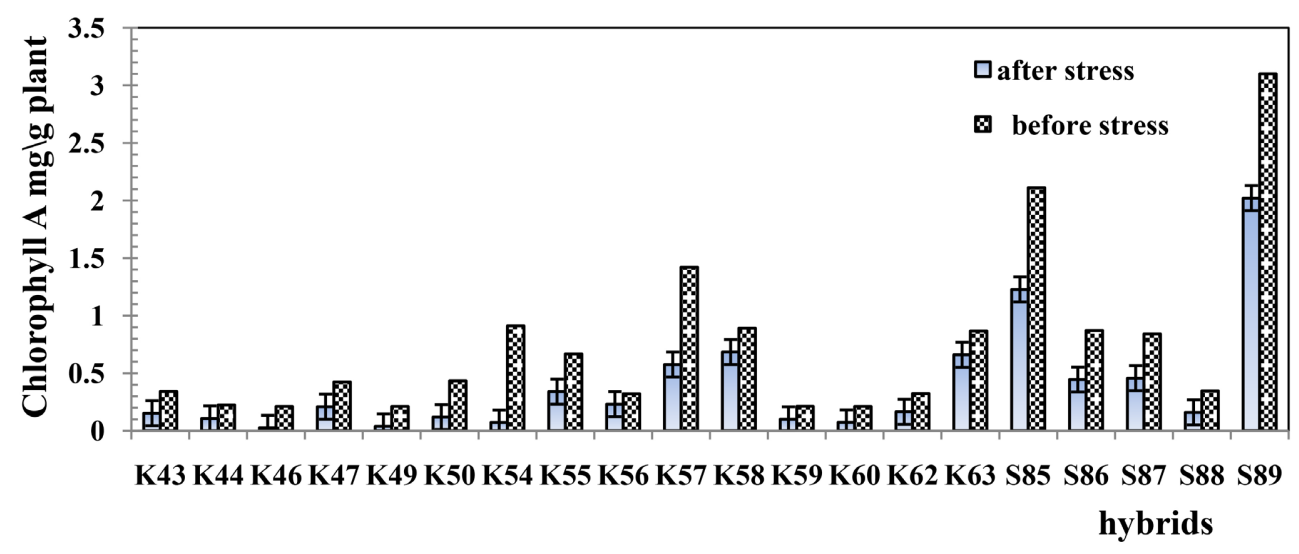

Figure 12. Chlorophyll A index in individuals exposed to calcareous stress $1 \mathrm{~mol}$.

The value of total chlorophyll in all individuals decreased after stress, as a result of stress with statistical significance. The highest value is $(2.78,1.89,1.023$, $0.931) \mathrm{mg} / \mathrm{g}$ plant of hybrids ( $\mathrm{S} 89, \mathrm{~S} 85, \mathrm{~K} 58$ and $\mathrm{K} 50$ ). The lowest value is (0.052) of K49 hybrid. According to the Critical Difference, the two hybrids S89 and $\$ 85$ outperformed all crosses, and the first one was significantly superior to the second (Figure 14). 


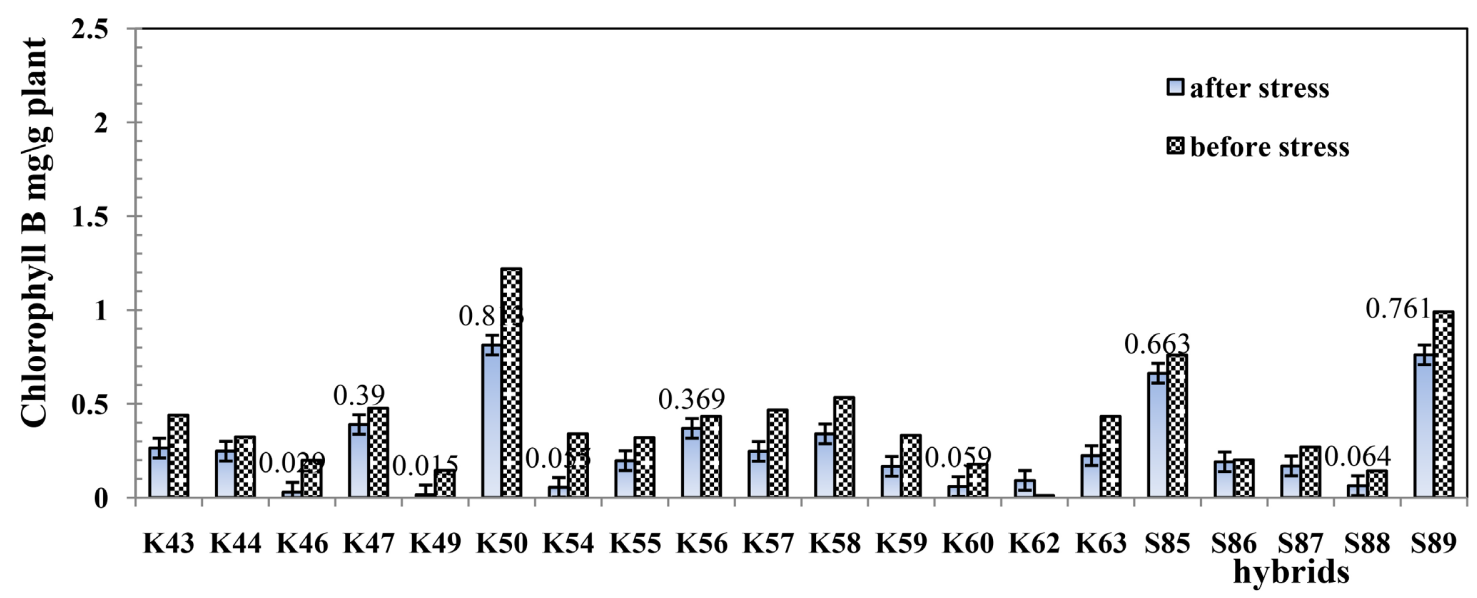

Figure 13. Chlorophyll B index in individuals exposed to calcareous stress $1 \mathrm{~mol}$.

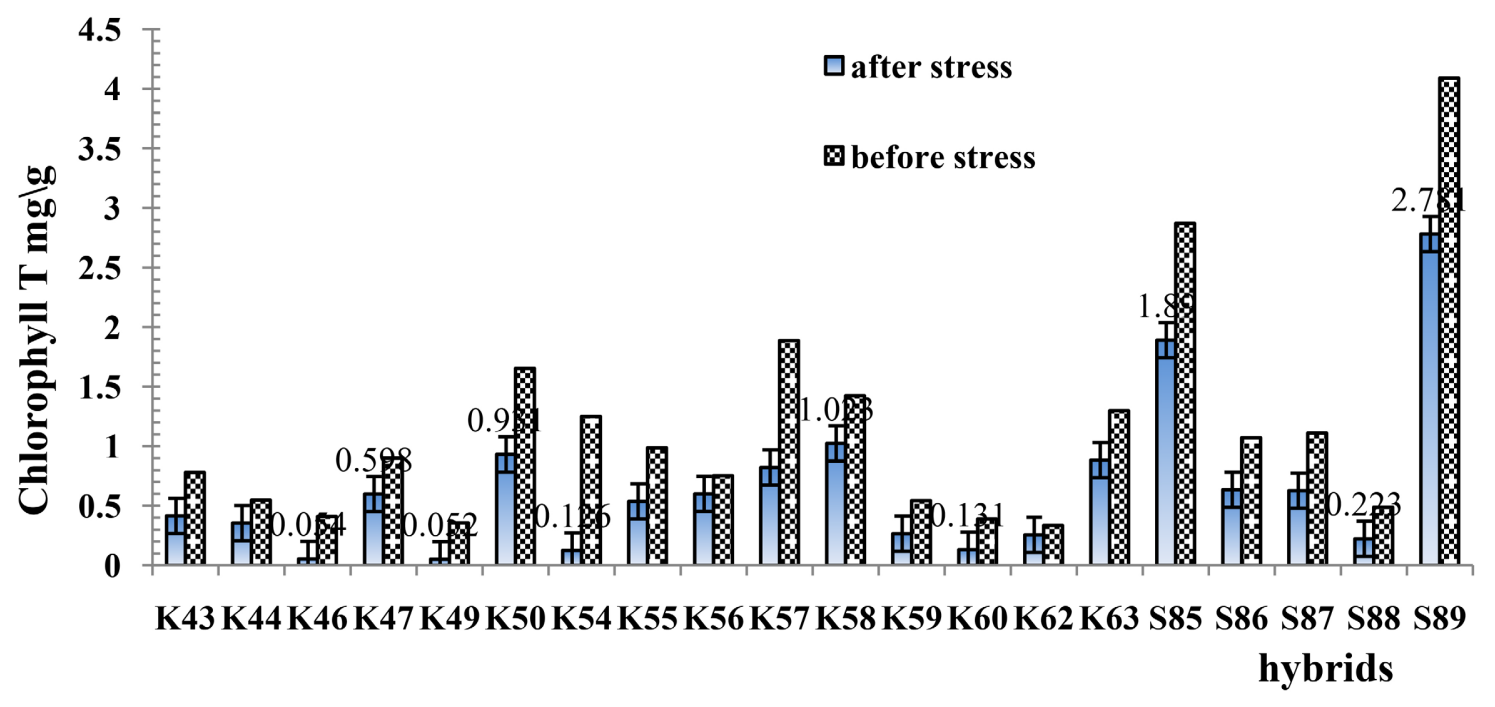

Figure 14. Chlorophyll T index in individuals exposed to calcareous stress $1 \mathrm{~mol}$.

\section{Calcareous stress $2 \mathrm{~mol}$}

Chlorophyll A

The value of Chl. A decreased in all individuals (seed parent Cleopatra mandarin and Sour orange) after calcareous stress, decrease is significant. The highest value is $1.584 \mathrm{mg} / \mathrm{g}$ for $\mathrm{S} 99,(0.801)$ for $\mathrm{S} 97$ and $(0.51) \mathrm{mg} / \mathrm{g}$ for S98 (the seed parent is Sour orange), the hybrids K69 and K76 are valued $(0.264,0.263)$ respectively which the seed parent is Cleopatra mandarin. According to Critical Difference, the hybrid S99 is significantly superior to all crosses followed by the hybrid S97 which is morally superior to the rest of the hybrids, the S98 hybrid is morally superior to the rest of the hybrids (Figure 15).

Chlorophyll B

The value of Chl. B decreased after stress with a high statistical significance (Figure 16), destroyed as a result of calcareous stress. The highest values are $(0.562,0.424,0.328,0.295,0.25,0.229) \mathrm{mg} / \mathrm{g}$ plant for hybrids (S99, S97, K65, K68, K72 and K70) respectively. The lowest values is (0.051) of hybrid K84. Ac- 
cording to Critical Difference, the hybrid S99 is significantly superior to all crosses, hybrid S97 is significantly superior to the remaining hybrids.

Chlorophyll T

Total chlorophyll decreased in all individuals after calcareous stress, this decrease is significant. The highest value is $(2.146,1.225,0.682,0.506,0.506) \mathrm{mg} / \mathrm{g}$ for (S99, S97, S98, K68, and K72), respectively. The lowest value is (0.126) for K84. According to Critical Difference, the superiority of S99 and S97 over all the studied hybrids is significant significance. The first hybrid outperformed the second. Hybrid S98 also outperformed all hybrids with high statistical significance, except for hybrids K68 and K72, no significant difference between the latter two (Figure 17).

When plotting the graph of the total chlorophyll and Proline values at the end of the experiment, the higher values of both total chlorophyll and Proline is for the most tolerant rootstocks compared to the sensitive ones, and the higher the sensitivity of the rootstocks is the lower of Proline, so total chlorophyll in their leaves (Figure 18 and Figure 19).

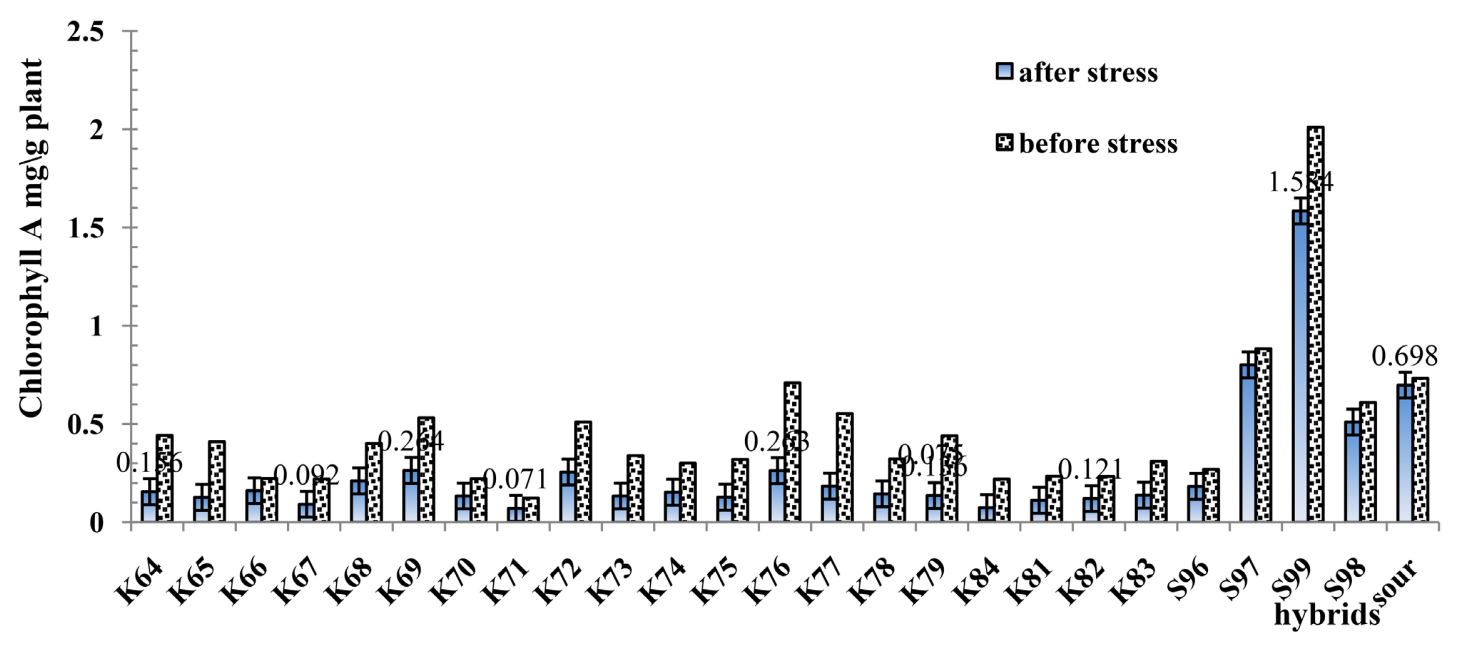

Figure 15. Chlorophyll A index in individuals exposed to calcareous stress $2 \mathrm{~mol}$.

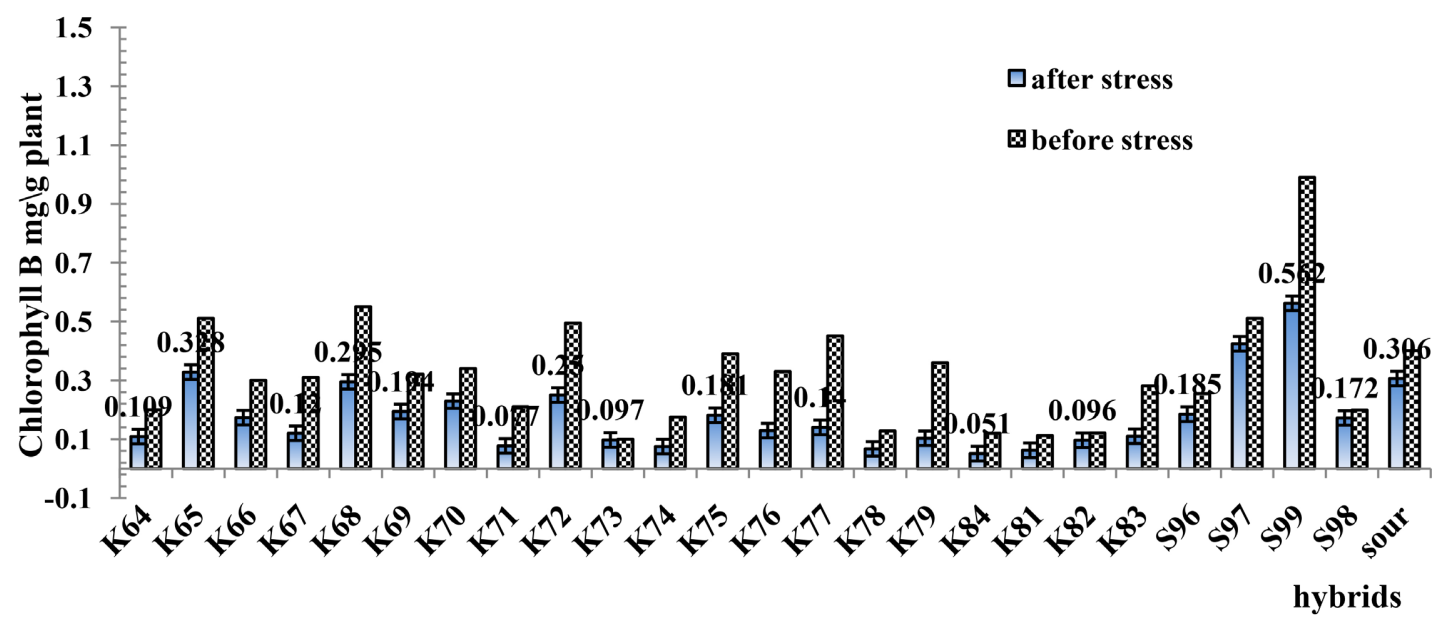

Figure 16. Chlorophyll B index in individuals exposed to calcareous stress 2 mol. 


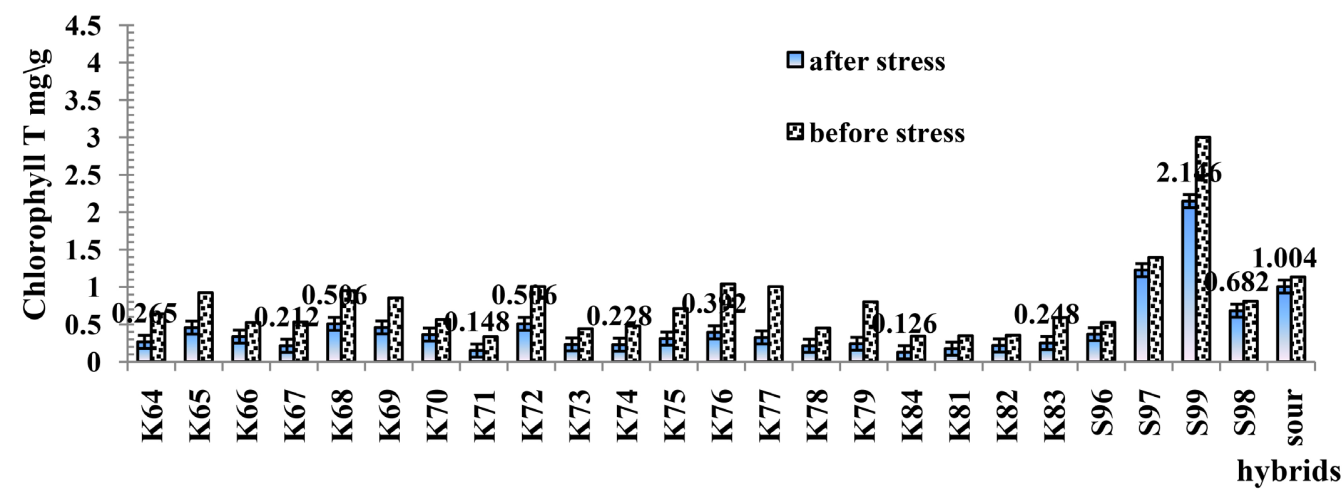

Figure 17. Chlorophyll T index in individuals exposed to calcareous stress $2 \mathrm{~mol}$.

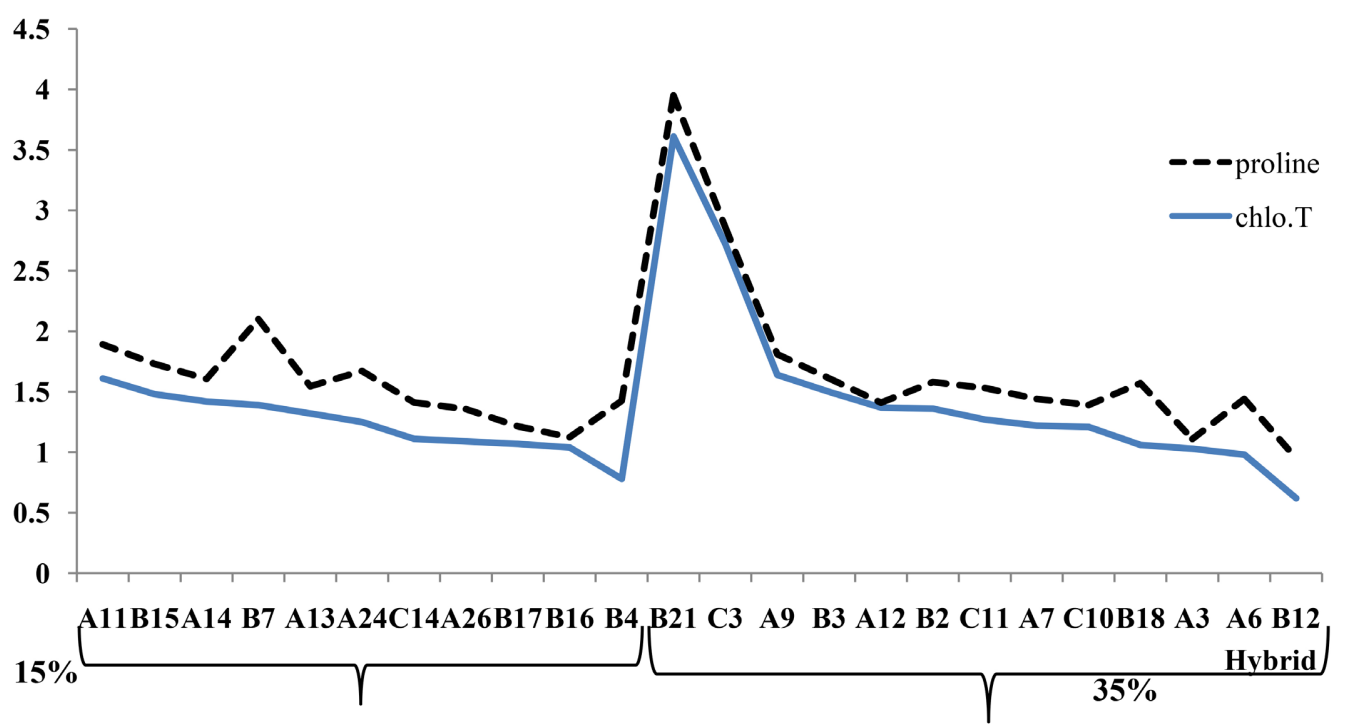

Figure 18. Relation between proline and Chlorophyll T of F1 seedlings under calcareous stress (15\%, $35 \%)$.

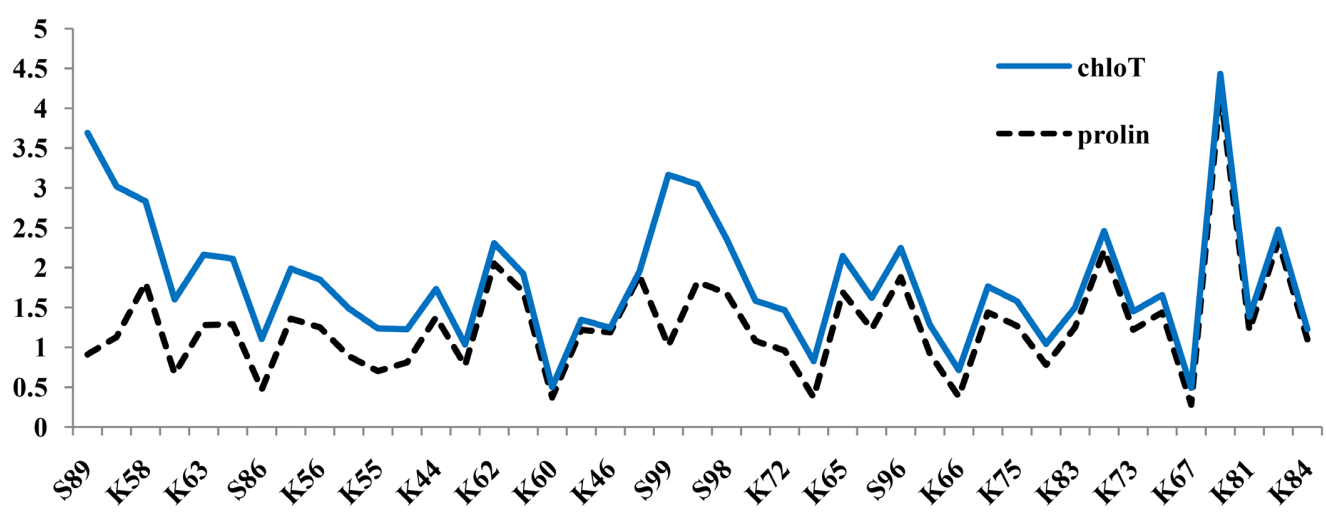

Figure 19. Relation between proline and Chlorophyll T of F1 seedlings under calcareous stress (1 mol, $2 \mathrm{~mol})$.

\subsection{Molecular Marker}

Seven SSR primers were tested for discrimination of hybrids from the nucellar seedlings of F1 (Figure 20). Tow SSR primers selected from TTA series TTA15, 
and TTA33 were not able to discriminate seedlings and generated single amplicon after PCR reaction, but the primers selected from CCSM series (CCSM13, CCSM17, CCSM18 and CCSM147) and TTA27 were able to differentiate sexual seedlings (Figure 18). [43] were able to identify hybrid with primers from TTA series. TTA15 proved useful for hybrid detection, but in our experiment only a

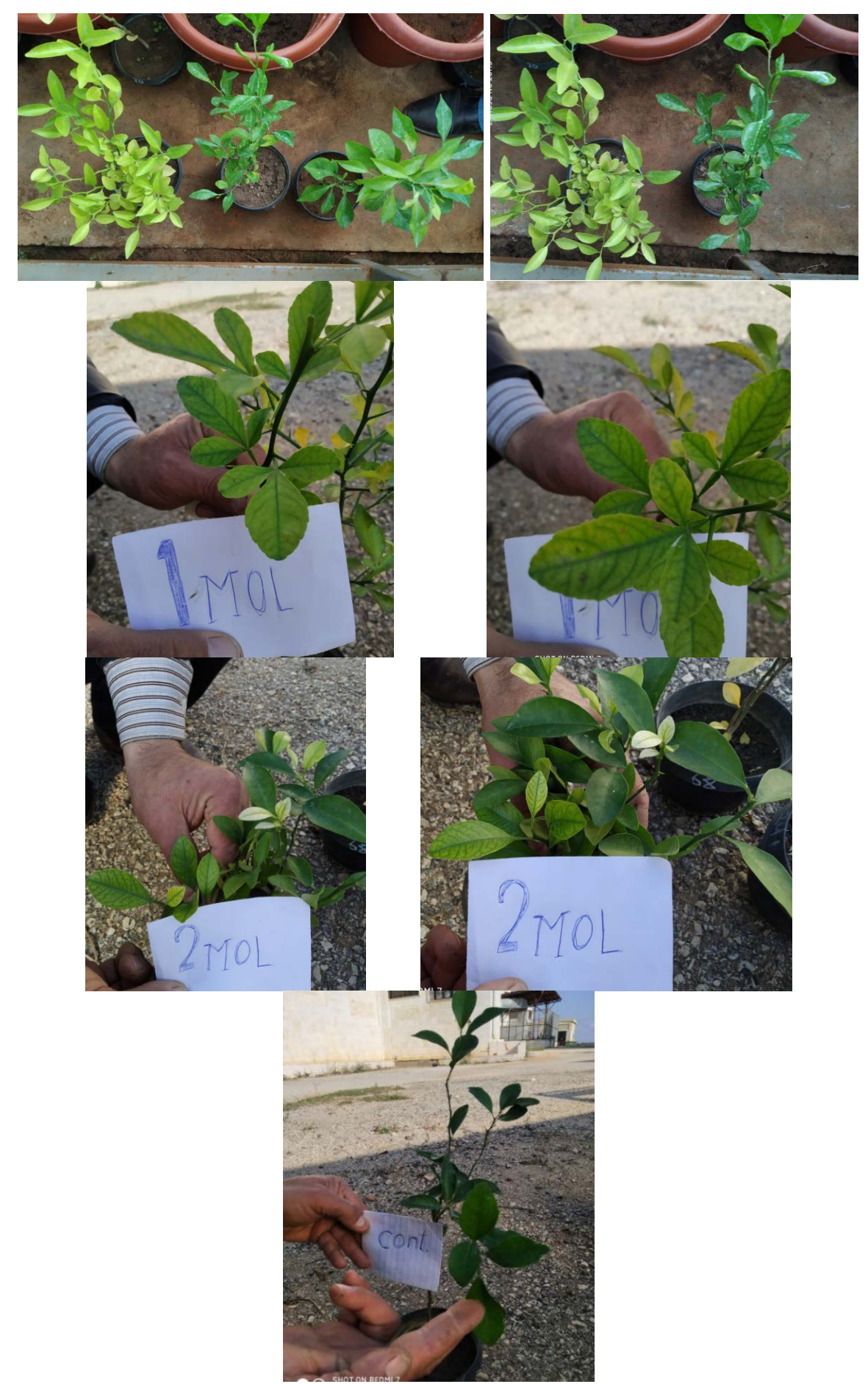

Figure 20. Visual symptoms of calcareous-induced chlorosis in individuales F1 exposed to calcareous stress $1 \mathrm{~mol}$ and $2 \mathrm{~mol}$. 
single amplicon was generated by all the seedlings without any noticeable polymorphism. Total 9 alleles were detected across loci. CSM13 amplified 2 loci with wider amplicon range of $950 \mathrm{bp}$ and $280 \mathrm{bp}$. CSM 17 generated two locus of 100 bp and $80 \mathrm{bp}$. CSM 18 generated one locus of $220 \mathrm{bp}$. CCSM 147 amplified one locus of $120 \mathrm{bp}$ and TTA27 generated one locus of $175 \mathrm{bp}$.

There is a similarity between individuals and parents of the absence or presence of the amplicon (Figure 21), therefore the individuals which have difference with the seed parent, those were regarded a hybrid. In our study, all the studied individuals recorded a difference with the seed parent and she was a hybrid.

According to Figure 22, the studied individuals were divided into two groups, a group that included individual $S 97$ independently, and a group $Z$ that included several clusters, including group Z1 individuals B, C, and S86 within one cluster, and individual A3 independently, and group Z2 that included individuals S107 and $\mathrm{C} 11$ within the binary and the other cluster which contained individual B12 separately, A and B21 that formed a binary

As for the genetic similarity values between individuals tolerant of calcareous stress, Table 5 shows the highest value was between individuals B21 and B12, reaching 0.875 , and the lowest value was 0.25 between individuals (S97 and B21) and individuals (S97 and A3).

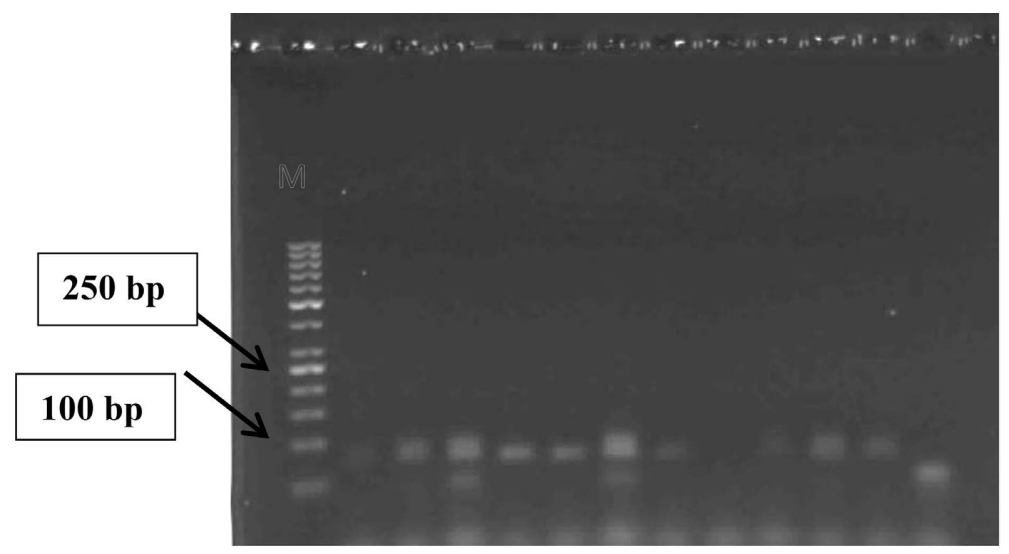

(a)

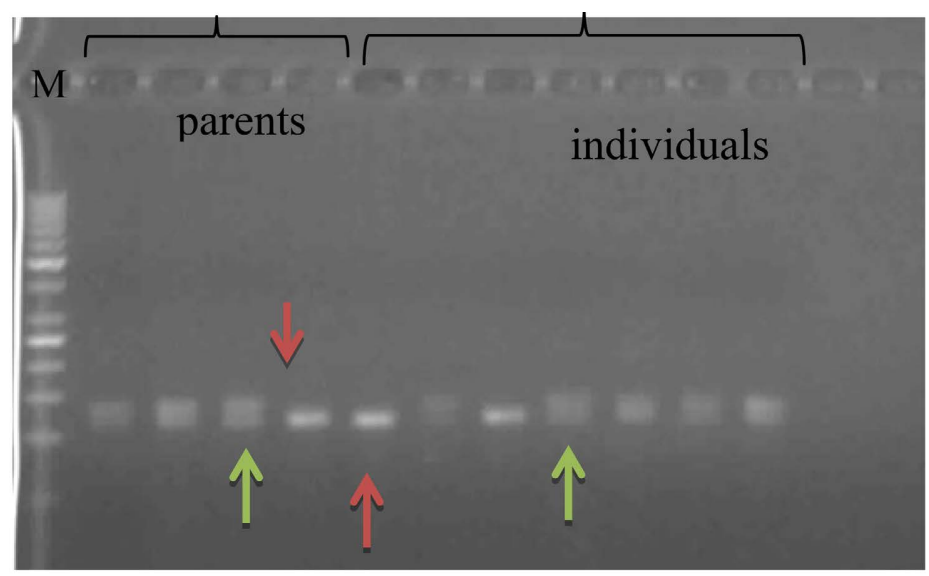

(b) 


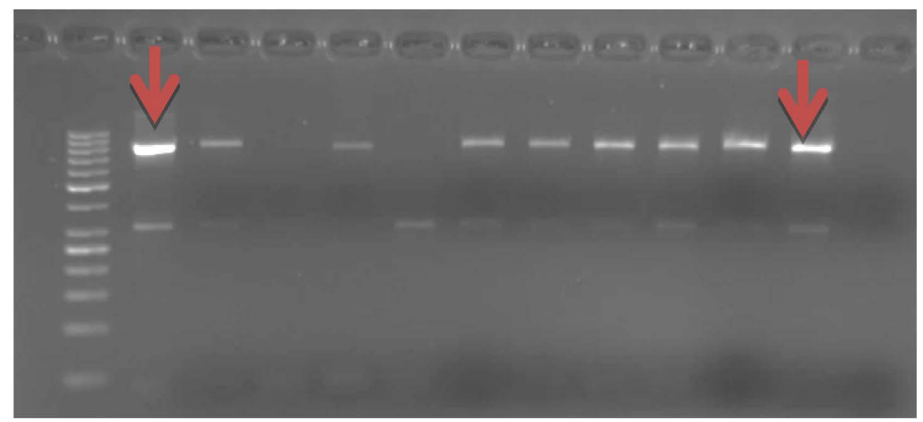

(c)

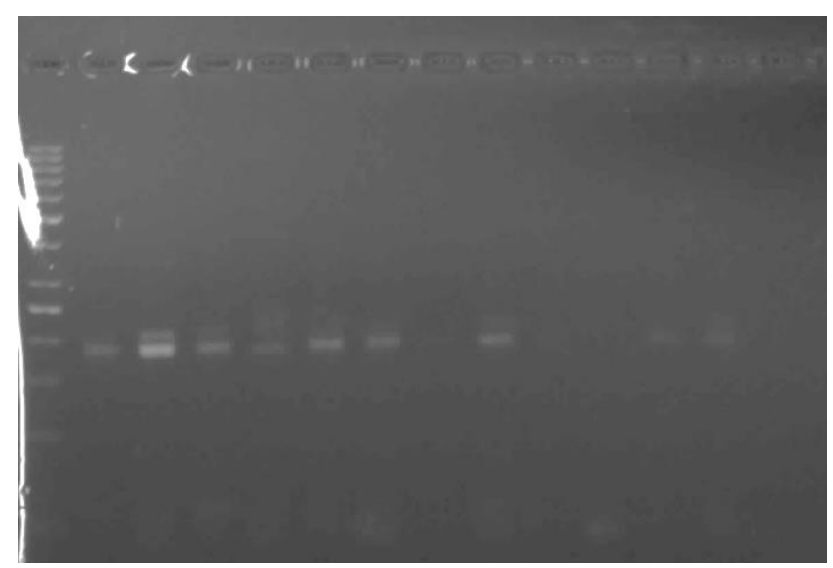

(d)

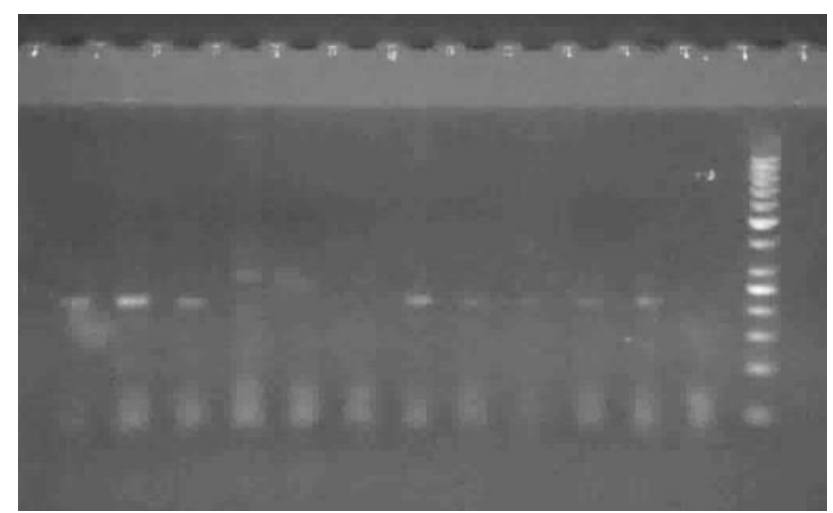

(e)

Figure 21. Polymorphic patterns obtained from seedlings f1 of the tolerant of SSR primers. (a) (Primer CSM17), (b) (Primer CSM147), (c) (Primer CSM13), (d) (Primer TAA27), (e) (Primer CSM18).

Table 5. Values of genetic similarity between individuals tolerant of calcareous stress due to SSR primers.

\begin{tabular}{ccccccccccc}
\hline & B & C & A & S86 & S97 & S107 & C11 & A3 & B12 & B21 \\
\hline B & 1.00 & & & & & & & & & \\
C & 0.75 & 1.00 & & & & & & & & \\
A & 0.50 & 0.50 & 1.00 & & & & & & & \\
S86 & 0.75 & 0.75 & 0.50 & 1.00 & & & & & & \\
\hline
\end{tabular}




\section{Continued}

\begin{tabular}{cccccccccccc}
\hline S97 & 0.375 & 0.625 & 0.375 & 0.375 & 1.00 & & & & & \\
S107 & 0.50 & 0.75 & 0.50 & 0.75 & 0.375 & 1.00 & & & & \\
C11 & 0.50 & 0.50 & 0.50 & 0.50 & 0.375 & 0.75 & 1.00 & & & \\
A3 & 0.625 & 0.375 & 0.625 & 0.625 & 0.25 & 0.375 & 0.375 & 1.00 & & \\
B12 & 0.50 & 0.50 & 0.75 & 0.50 & 0.375 & 0.75 & 0.75 & 0.375 & 1.00 & \\
B21 & 0.375 & 0.375 & 0.875 & 0.375 & 0.25 & 0.625 & 0.625 & 0.50 & 0.875 & 1.00 \\
\hline
\end{tabular}

calcarous tolerance

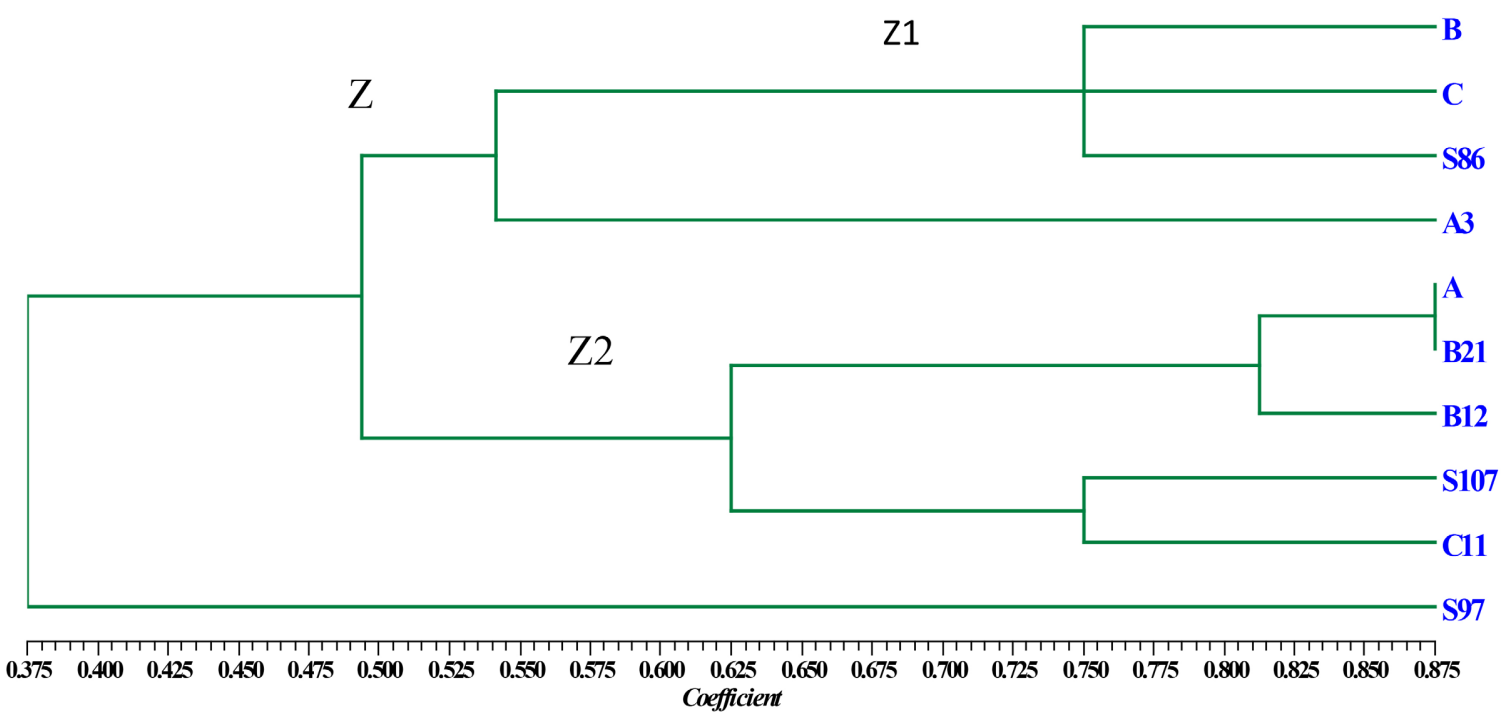

Figure 22. Cluster analysis and dendrogram of genetic distance based on SSR data in individuals tolerant of calcareous stress.

\section{Discussion}

According to variation in the behavior of the individuals of $\mathrm{F} 1$ exposed to calcareous stress, some of the hybrids were not affected by the stress $15 \%$, but rather the concentration of total chlorophyll increased as the hybrids B7, B17 and B15 (Sour orange $\hat{\delta} \times$ Cleopatra mandarin + ), Which parents are known tolerant to calcareous stress and A14 (Sour orange $\delta \times$ Trifoliate orange + ) its pollen parent is also tolerant, this applied stress is low for them, so chlorophyll was not affected at this stress, the [22] found that chlorophyll was damaged at high level of stress.

In 35\%, total chlorophyll increased in $\mathrm{F} 1$ individuals of the same parents as B21, B3, B2 (Sour orange $\hat{O} \times$ Cleopatra mandarin )), and C3 (Cleopatra mandarin $\delta \times$ Sour orange + ). On the other hand, we observed the accumulation of proline in all hybrids in all stress treatments, which protects the plant cells from damage, as a protective osmolyte compound in response to stress, it has an important role at the cellular level in the internal osmotic of plants exposed to stress [10] [12] [40], we obtained tolerant hybrids by crossing (Sour orange $\times$ Cleopatra mandarin). 
While watering method ( $1 \mathrm{~mol}$ and $2 \mathrm{~mol}$ ) calcareous solution, caused clear symptoms of Lime induced chlorosis (Figure 19)associated with a significant deterioration of chlorophyll, the reason may be that pollen seed is Trifoliate orange (sensitive), the trifoliate hybrids suffer severely from chlorosis in calcareous soil, while no symptoms on Cleopatra mandarin and Sour orange hybrids [24] [25] [26].

Long term (two years) made the individuals able to adapt to conditions of calcareous stress, and tolerant ones kept the Chlorophyll $\mathrm{T}$ in $15 \%, 35 \%$ treatments, according to [23] the values of total chlorophyll were significantly higher in resistant rootstocks than in sensitive ones. In contrast, the short term (two months) of application stress show clear symptoms of Lime-induced chlorosis are noted in Figure 20, these symptoms are due to deterioration of chlorophyll, and the chlorosis varies between plants depending on several factors, including genetic and the surrounding conditions [19] [20].

The careful analysis of different groups of parents is essential for the progress of citrus breeding programs and this made the high accuracy of the SSR primers effective in identifying the vegetative plantings by matching them to the parents, the mother.

\section{Acknowledgements}

This research was supported by General Commission Science Agricultural Research, Ministry of Agriculture, Syria.

\section{Conflicts of Interest}

The authors declare no conflicts of interest regarding the publication of this paper.

\section{References}

[1] Ministry of Agriculture (2019) Statistics for the Season 2019. Ministry of Agriculture, Damascus.

[2] Pestana, M., De Varennes, A., Abadia, J. and Faria EA. (2005) Differential Tolerance to Iron Deficiency of Rootstocks Grown in Nutrient Solution. Scientia Horticulturae, 104, 25-36. https://doi.org/10.1016/j.scienta.2004.07.007

[3] Swingle, W.T. and Reece, P.C. (1936) The Botany of Citrus and Its Wild Relatives. in: The Citrus Industry. In: Reuther, W., Weber, H.J. and Batchelor, L.D., Eds., History, World Distributions, Botany and Varities, University of California Press, Berkeley, 190-243.

[4] Elkhateeb, A. (2009) The Effect of Five Citrus Rootstocks on The Growth Productivity and Quality of Orange Fruits Valencia Orange. Basil Al-Assad Journal for Engineering Sciences, 25, 65-85.

[5] Davies, F.S. and Albrigo, L.G. (1994) Citrus Crop Production Science in Horticulture 2. CAB, International, Red Wood Books, Wiltshir, 73-107.

[6] Akgol, M., Simsek, O., Donmez, D. and Kacar, Y.A. (2017) On Overview of in Vitro Haploid Plant Production in Citrus. American Journal of Plant Biology, 2, 19-23.

[7] Moreno, J.J., Lucena, J.J. and Carpena, O. (1996) Effect of the Iron Supply on the 
Nutrition of Different Citrus Variety/Rootstock Combinations Using DRIS. Journal of Plant Nutrition, 19, 689-704. https://doi.org/10.1080/01904169609365153

[8] Tan, F.Q., Tu, H., Liang, W.J., Long, J.M., Wu, X.M., Zhang, H.Y. and Guo, W.W. (2015) Comparative Metabolic and Transcription Alanalysis of Adoubled Diploid and Its Diploid Citrus Rootstock (Citrus junos cv. Ziyang xiangcheng) Suggests Its Potential Value for Stress Resistance Improvement. BMC Plant Biology, 15, Article No. 89. https://doi.org/10.1186/s12870-015-0450-4

[9] Oustric, J., Morillon, R., Francois, L., Herbette, S., Lourkisti, R., Giannettini, J., Berti, L. and Santini, J. (2017) Tetraploid Carrizo Citrange Rootstock (Citrus sinensis Osb x Poncirus trifoliata L. Raf.) Enhances Natural Chilling Stress Tolerance of Common Clementine (Citrus clementina Hort. ex Tan). Journal of Plant Physiolo$g y, 214,108-115$. https://doi.org/10.1016/j.jplph.2017.04.014

[10] Young, A. and Britton, G. (1993) Carotenoid in Photosynthesis. 1st Edition, Chapman and Hall, London, 98. https://doi.org/10.1007/978-94-011-2124-8

[11] Arbona, V., Manzi, M., de Ollas, C. and Gómez-Cadenas, A. (2013) Metabolomics as a Tool to Investigate Abiotic Stress Tolerance in Plants. International Journal of Molecular Sciences, 14, 4885-4911. https://doi.org/10.3390/ijms14034885

[12] Signorelli, S. (2016) The Fermentation Analogy: A Point of View for Understanding the Intriguing Role of Proline Accumulation in Stressed Plants. Frontiers in Plant Science, 7, Article No. 1339. https://doi.org/10.3389/fpls.2016.01339

[13] Kavi kishor, P.B., Hima kumari, P., Sunita, M.S.L. and Sreenivasulu, N. (2015) Role of Proline in Cell Wall Synthesis and Plant Development and Its Implications in Plantontogeny. Frontiers in Plant Science, 6, Article No. 544.

https://doi.org/10.3389/fpls.2015.00544

[14] Zandalinas, S.I., Rivero, R.M., Martínez, V., Gómez-Cadenas, A. and Arbona, V. (2016) Tolerance of Citrus Plants to the Combination of High Temperatures and Drought is Associated to the Increase in Transpiration Modulated by a Reduction in Abscisic Acid Levels. BMC Plant Biology, 16, Article No. 105. https://doi.org/10.1186/s12870-016-0791-7

[15] Vives- Peris, V., Gómez- Cadenas, A. and Pérez Clemente, R.M. (2017) Citrus Plants Exude Proline and Phytohormones under Abiotic Stress Conditions. Plant Cell Report, 36, 1971-1984. https://doi.org/10.1007/s00299-017-2214-0

[16] Guidi, L., Tattini, M. and Landi, M. (2017) How Does Chloroplast Protect Chlorophyll Against Excessive Light? In: Jacob-Lopes, E., Queiroz Zepka, L. and Queiroz, M.I., Eds., Chlorophyll, IntechOpen, London, 21-36. https://doi.org/10.5772/67887

[17] Porra, R.J. (1991) Recent Advances and Re-Assessments in Chlorophyll Extraction and Assay Procedures for Terrestrial, Aquatic, and Marine Organisms, Including Recalcitrant Algae. In: Scheer, H., Ed., Chlorophylls, CRC Press, Boca Raton, Ann Arbor, Boston, London, 32-57.

[18] Vicas, S.I., Laslo, V., Pantea, S. and Bandict, G. (2010) Chlorophyll and Carotenoids Pigments from Mistletoe (Viscum Album) Leaves Using Different Solvents. Analele Universității din Oradea-Fascicula Biologie, 17, 213-218.

[19] Tripathi, A.K. and Gautam, M. (2007) Biochemical Parameters of Plants as Indicators of Air Pollution. Journal of Environmental Biology, 28, 127-132.

[20] Khan, M.A., Idrees, M. and Shahab, D. (2007) Chlorophyll Content in Some Citrus Species. VEGETOS, 20, 7-8.

[21] Costache, M.A., Campeanu, G. and Neata, G. (2012) Studies Concerning the Extraction of Chlorophyll and Total Carotenoids from Vegetables. Studies Concerning the Extraction of Chlorophyll and Total Carotenoids from Vegetables, 17, 7702-7708. 
[22] Ruban, A.V. (2015) Evolution under the Sun: Optimizing Light Harvesting in Photosynthesis. Journal of Experimental Botany, 66, 7-23. https://doi.org/10.1093/jxb/eru400

[23] Forner-Giner, M.A., Llosa, M.J., Carrasco, J.L., Amador, M.A., Navarro, L. and Ancillo, G. (2010) Differential Gene Expression Analysis Provides New Insights into the Molecular Basis of Iron Deficiency Stress Response in the Citrus Rootstock Poncirus trifoliata (L.) Raf. Journal of Experimental Botany, 61, 483-490. https://doi.org/10.1093/jxb/erp328

[24] Incesu, M., Yesiloglu, T., Tuzcu, O., Cimen, B. and Yilmaz, B. (2016) Response of Citrus Rootstocks to Iron Deficiency under High pH Conditions. Citrus Research \& Technology, 37, 66-75. https://doi.org/10.4322/crt.ICC056

[25] Ferrarezi, R.S., Bataglia, O.C., Furlani, R.P. and Schammass, E.S. (2007) Iron Sources for Citrus Rootstock Development Grown on Pine bark/Vermiculite Mixed Substrate. Scientia Agricola, 64, 520-531. https://doi.org/10.1590/S0103-90162007000500010

[26] Castle, W.S. and Nunnallee, J. (2009) Screening Citrus Rootstocks and Related Selections in Soil and Solution Culture for Tolerance to Low-Iron Stress. Hort Science, 44, 638-645. https://doi.org/10.21273/HORTSCI.44.3.638

[27] Tautz, D. (1989) Hypervariability of Simple Sequences as a General Source for Polymorphic DNA Markers. Nucleic Acids Research, 17, 6463-6471. https://doi.org/10.1093/nar/17.16.6463

[28] Goldstein, D.B., Roemer, G.W., Smith, D.A., Reich, D.E., Bergman, A. and Wayne, R.K. (1999) The Use of Microsatellite Variation to Infer Population Structure and Demographic History in a Natural Model System. Genetics, 151, 797-801. https://doi.org/10.1093/genetics/151.2.797

[29] Weissenbach, J., Gyapay, G., Dib, C., Vignal, A., Morissette, J., Millasseau, P., Vaysseix, G. and Lathrop, M.A. (1992) Second-Generation Linkage Map of the Human Genome. Nature, 359, 794-801. https://doi.org/10.1038/359794a0

[30] Thomas, V.M., Clark, C.K. and Schuldt, C.M. (1994) Effects of Substituting Feather Meal for Soybean Meal on Ruminal Fiber Fermentation and Lamb and Wool. Growth Journal of Animal Sciences, 72, 509-514. https://doi.org/10.2527/1994.722509x

[31] Ruiz, C., Breto, M.P. and Asins, M.J. (2000) A Quick Methodology to Identify Sexual Seedlings in Citrus Breeding Programs Using SSR Markers. Euphytica, 112, 89-94. https://doi.org/10.1023/A:1003992719598

[32] Novelli, V.M., Cristofani, M., Souza, A. and Machado, M.A. (2006) Development and Characterization of Polymorphic Microsatellite Markers for the Sweet Orange (Citrus sinensis L. Osbeck). Genetics and Molecular Biology, 29, 90-96. https://doi.org/10.1590/S1415-47572006000100018

[33] Mondal, B., Pramanick, S., Saha, R. and Karmakar, M. (2015) Application of Simple Sequence Repeat Markers for Demarcation of Citrus reticulata Nucellar and Hybrid Seedlings. International Journal of Biosciences, 6, 128-133.

https://doi.org/10.12692/ijb/6.2.128-133

[34] Carrillo-Medrano, H.S., Gutierrez-Espinosa, A.M., Robles-González, M.M. and Cruz-Izquierdo, S. (2018) Identification of Mexican lemon Hybrids Using Molecular markers SSR. Revista Mexicana de Ciencias Agrícolas, 9, 11-23. https://doi.org/10.29312/remexca.v9i1.844

[35] Hutchison, D.J. (1977) Influence of Rootstock on the Performance of Valencia Sweet Orange. Proceedings of the Inter American Tropical Horticulture 1977, Vol. 
2, Orlando, 523-525.

[36] Nava ayala, J. and Monter, A.V. (1994) Nursery Performance of Rootstocks Tolerant to Citrus Tristeza. Proceedings of the Inter American Tropical Horticulture, 38, 86-89.

[37] Castle, W.S. (1987) Citrus Rootstocks. John Wiley and Sons, New York.

[38] Zhu, S., Wang, F., Shen, W., Jiang, D. and Hong, Q. (2015) Genetic Diversity of Poncirus and Phylogenetic Relationships with Its Relatives Revealed by SSR and SNP/InDel Markers. Acta Physiologiae Plantarum, 37, Article No. 141. https://doi.org/10.1007/s11738-015-1890-z

[39] Forner, J.B., Forner-Giner, M.A. and Alcaide, A. (2003) Forner-Alcaide 5 and Forner-Alcaide 13: Two New Citrus Rootstocks Released in Spain. HortScience, 38, 629-630. https://doi.org/10.21273/HORTSCI.38.4.629

[40] Bates, L.S., Waldren, R.P and Tear, I.D. (1973) Rapid Determination of Free Proline for Water Stress Studies. Plant and Soil, 39, 205-207. https://doi.org/10.1007/BF00018060

[41] Gogoi, M. and Basumatary, M. (2018) Estimation of the Chlorophyll Concentration in Seven Citrus Species of Kokrajhar District, BTAD, Assam, India. Tropical Plant Research, 1, 83-87. https://doi.org/10.22271/tpr.2018.v5.i1.012

[42] Rohlf, F.J. (1993) NTSYS-PC Numerical Taxonomy and Multivariate Analysis System Version 1-80. Exeter Software, Setauket.

[43] Ahmad, M., Javaid, R. and Ghafoor, A. (2012) Identification of Mandarin x Orange Hybrids Using Simple-Sequence Repeat Markers. Journal of Agricultural Research, 50, 225-232. 